\title{
The Ongoing Question of Where Clinicians Should Place the Nebulizer in the Ventilator Circuit: This Time With Epoprostenol
}

In this issue of Respiratory CARe, Anderson and colleagues ${ }^{1}$ determined the differences in epoprostenol deposition based on nebulizer position in the ventilator circuit in an adult lung model using vibrating mesh technology. The study involved placing the nebulizer at 4 different positions in the ventilator circuit (humidifier inlet, humidifier outlet, within the inspiratory limb, and between the endotracheal tube and the Y-piece) and collecting the aerosolized epoprostenol on a filter located at the distal end of the endotracheal tube. With this particular model, the authors found that the highest delivery of epoprostenol occurred when the nebulizer was situated at the humidifier inlet, with the humidifier outlet position being a close second.

I commend the efforts of the authors in their attempt to determine the optimal nebulizer position for epoprostenol delivery. A study such as this is especially important because the use of epoprostenol is very attractive from a financial perspective compared to the use of inhaled nitric oxide. In addition, although this has not been documented, I strongly suspect that the use of epoprostenol in place of inhaled nitric oxide is increasing among institutions in the United States. To that end, it is important to determine best methods to optimize deposition.

The study by Anderson et al, however, does not provide us with a definitive answer as to where to place the nebulizer in the ventilator circuit. In their model, filters were used to collect the epoprostenol, which means that we know the amount of epoprostenol that was delivered to the filter, but we do not the particle size being delivered. We have no way of knowing whether any or all of the drug delivered to the filters would have made it past the larger conducting airways. Second, the same controller was used at each specific site. What appears to be unknown is whether there were any inherent functional differences between the

Mr Davies discloses relationships with Resmed and Bayer.

Correspondence: Duke University Health System, Box 3911, DUH, Durham, North Carolina 27710. E-mail: john.davies@ duke.edu.

DOI: $10.4187 /$ respcare. 05884
4 controller units that could potentially explain some of the results. The functional decay of the mesh in the nebulizers is also unknown. Some more viscous medications

See the Original Study on Page 1387

have the potential to eventually clog the mesh and cause the nebulizer to fail. Fortunately, the researchers didn't experience the same level of nebulizer failure rate as Gowda and colleagues. ${ }^{2}$ In the Gowda study, a $25 \%$ to $30 \%$ failure rate of the nebulizer was reported when nebulizing sterile and distilled water.

While concerns remain with regard to the reliability of the nebulizers and controller units, the work by Anderson and colleagues mirrors that of Ari et $\mathrm{al}^{3}$ and Berlinski and Willis, ${ }^{4}$ suggesting that optimal placement of the nebulizer is pre-humidifier. This study represents an encouraging step in the right direction for future use of aerosolized epoprostenol as an alternative to inhaled nitric oxide. More research is needed in the area of in vivo drug deposition to further understand the various factors associated with optimal drug delivery.

John D Davies MA RRT FAARC Respiratory Care Services Duke Health System Durham, North Carolina

\section{REFERENCES}

1. Anderson AC, Dubinsky MN, Fiorina KA, Quintana V, Kaplan CA, Vines DL. The effect of nebulizer position on aerosolized epoprostenol delivery in an adult lung model. Respir Care 2017; Jul 18. pii: respcare.05344. doi: 10.4187/respcare.05344. [Epub ahead of print]

2. Gowda AA, Cuccia AD, Smaldone GC. Reliability of vibrating mesh technology. Respir Care 2017;62(1):65-69.

3. Ari A, Atalay OT, Harwood R, Sheard MM, Aljamhan EA, Fink JB. Influence of nebulizer type, position, and bias flow on aerosol drug delivery in simulated pediatric and adult lung models during mechanical ventilation. Respir Care 2010;55(7):845-851.

4. Berlinski A, Willis RJ. Albuterol delivery by 4 different nebulizers placed in 4 different positions in a pediatric ventilator in vitro model. Respir Care 2013;58(7):1124-1133. 